\title{
Procesos de producción, emisión y recepción de las noticias extranjeras en la TV chilena
}

\author{
William PORATH CAMPOS \\ Pontificia Universidad Católica de Chile \\ wporath@uc.cl \\ Constanza MuJICA Holley \\ Pontificia Universidad Católica de Chile \\ mcmujica@uc.cl \\ Francisco MaldonAdo UlloA \\ Pontificia Universidad Católica de Chile \\ fjmaldon@uc.cl
}

Recibido: 07/04/2011

Aceptado: 20/12/2011

\begin{abstract}
Resumen
El trabajo analiza la importancia que se otorga en la televisión chilena a las noticias extranjeras y los factores que inciden en la selección de las noticias del exterior que se emiten en Chile. Esto desde la perspectiva de los editores y periodistas de TV, desde la percepción del público y desde el análisis de los contenidos emitidos por dos estaciones. Todas las etapas del estudio coinciden en destacar la primacía de contenidos locales por sobre los foráneos en la TV chilena, así como la relevancia de factores como el impacto y la cercanía emocional al momento de determinar qué noticias extranjeras serían atractivas para el público nacional. El estudio constató además un alto nivel de domesticación y un bajo nivel de contextualización de las noticias extranjeras en los noticiarios chilenos.
\end{abstract}

Palabras clave: Televisión. Chile. Noticias extranjeras. Selección de noticias.

\section{Production, Broadcast and Reception Processes of Foreign News in Chilean TV}

\begin{abstract}
This paper analyzes the importance given to foreign news in Chilean television and the factors that condition the selection of foreign news in Chilean newscasts. It takes into account the perspective of television journalists and editors, the public's perception and the content analysis of newscasts aired by two broadcasters. All the stages of this study point out the priority given to domestic contents over foreign contents, and the relevance of elements like impact and emotional proximity in the determination of which foreign news will be aired. The study verified a high level of domestication and a low level of context in foreign news aired in Chilean newscasts.

Keywords: Television. Chile. Foreign news. News selection.

\section{Referencia normalizada}

PORATH CAMPOS, William; MUJICA HOLLEY, Constanza; y MALDONADO ULLOA, Francisco (2012): "Procesos de producción, emisión y recepción de las noticias extranjeras en la TV chilena". Estudios sobre el mensaje periodístico. Vol. 18, núm. 1, págs.: 353-370. Madrid, Servicio de Publicaciones de la Universidad Complutense.
\end{abstract}

Sumario: 1. Introducción. 2. El presente estudio. 3. Metodología. 4. Cuantificación y valoración de las noticias extranjeras en la televisión. 5. La proximidad como factor de selección y de interés por las noticias extranjeras. 6. Impacto y sensacionalismo: atracción de audiencias masivas. 7. Domesticación. 8. Contexto. 9. Conclusiones generales. 10. Referencias bibliográficas.

\section{Introducción}

Casi no se discute que en la actualidad la TV es, por mucho, la principal fuente de noticias para la mayoría de la gente, incluso con la creciente curva de usuarios de Inter- 
net. El público -a nivel internacional y también en Chile- tiende a reconocer a la televisión como su principal fuente de información. En Chile, el $79 \%$ de la población consume televisión abierta todos los días. En tanto, el 74,9\% de los chilenos considera que la televisión es su principal fuente de información sobre el mundo. La TV abierta es el medio más utilizado para este fin, superando casi en siete veces a su más cercano seguidor, la televisión de pago $(11,3 \%)$. Más atrás queda la radio: sólo un $4 \%$ de la población la considera como una fuente frecuente para informarse de lo que está pasando fuera del país (CNTV, 2005).

El consumo masivo de este medio de comunicación electrónico pone de relieve sus características propias. La televisión rompe la lógica de la copresencialidad en la comunicación, pues a través de ella las acciones son visibles para un mayor número de individuos en contextos dispersos, entregando imágenes e información a individuos ubicados en lugares alejados. THOMPSON sostiene que de esta manera los mass media, en especial la televisión, crean una nueva esfera pública donde se genera un campo de visión distinto del que los individuos tienen en sus contextos cotidianos, una nueva propiedad pública que es el espacio visible. Allí se da un intercambio simbólico en una interacción que ubica a las relaciones sociales como base de la sociedad moderna. Al prender la TV podemos aprender de lo que ocurre y esa información guiará nuestras acciones. La televisión es una fuente de poder simbólico generalizado que transmite ideas de mundo y un nuevo tipo de visibilidad: aquello que se ve en la TV es lo público, lo que existe, lo que se conoce. En consecuencia, el campo de visión está estructurado por las empresas mediáticas de la TV (THOMPSON, 1995).

Numerosos son los formatos de noticiarios de televisión desarrollados a lo largo del tiempo: locales y nacionales; generales y específicos (por ejemplo, económicos, deportivos, etc.); así como boletines breves y transmisiones continuas, 24 horas al día los siete días de la semana. Pese a la gran variedad, siempre han existido coincidencias entre todos los formatos informativos, especialmente en la revisión de noticias individuales (Stevenson y Cole, 1984a y 1984b). En la mayoría de los países, la mayor parte de las noticias de TV están referidas a personas, asuntos o acontecimientos (a menudo pseudo acontecimientos, por ejemplo, conferencias de prensa y otros actos programados por las autoridades de manera que parezcan espontáneos) de la arena doméstica, es decir, sobre la ciudad, la región o el país donde transmite la estación. Pero en grado variable, los noticiarios también contienen informes sobre acontecimientos o asuntos que han ocurrido (u ocurrirán) en otro país, cercano o lejano. En algunas estaciones, tales informes sobre acontecimientos extranjeros pueden comprender un segmento muy pequeño del noticiario o en otras una proporción significativa. Estos informes ocupaban el $34 \%$ de la cobertura de las principales cadenas de la televisión estadounidense entre 1982 y 1984 (WhITNEY et. al, 1989; GolAn, 2006), aunque este valor tiende a decrecer (RIFFE y BUDIANTO, 2001). En el caso de Chile, para el año 2000 las noticias internacionales representaban el 12,6\% (MARÍN, 2001).

\section{El presente estudio}

Este trabajo se inserta en el proyecto Foreign TV News Around the World, que cuenta con la participación de investigadores de 17 países, encabezados por el Dr. Akiba 
Cohen de la Universidad de Tel Aviv, Israel ${ }^{1}$. En el caso de Chile, éste fue realizado por los autores de este artículo y financiado por el Fondo Nacional de Desarrollo Científico y Tecnológico de Chile, FONDECYT (Proyecto número 1080047). El proyecto pretende analizar la incidencia y tratamiento que tienen en el trabajo informativo de la televisión las noticias que provienen del extranjero y el valor asignado a ellas en las sociedades de los diferentes países participantes. Para ello se propuso investigar el tema desde tres dimensiones: el contenido efectivo de las noticias extranjeras en televisión, las expectativas del público y el proceso de toma de decisiones en los medios. Estos objetivos se persiguieron a través de cuatro metodologías diferentes, las que se desarrollaron consecutivamente: análisis de contenido para estudiar una muestra de cuatro semanas de los noticieros centrales de dos canales seleccionados; una encuesta de población general (mayores de 18 años) de centros urbanos; focus groups a segmentos de esa misma población; y entrevistas en profundidad a editores y periodistas responsables de las noticias internacionales de los canales en estudio. En ese sentido el proyecto espera ser un aporte metodológico, ya que se analizaron conjuntamente los tres elementos básicos de la comunicación de masas -emisor, mensaje y receptor-, un modelo que no es habitual en las investigaciones sobre medios, en general, y sobre noticias, en particular (BRAMAN y COHEN, 1990).

En este artículo se presenta un avance de los resultados finales del proyecto para el capitulo chileno del proyecto global.

\section{Metodología}

El presente estudio hace una definición básica de noticias extranjeras como aquellas que suceden fuera de las fronteras del país de emisión. Este concepto no considera distinciones por área temática, sólo toma en cuenta el origen geográfico de la información emitida y, por lo mismo, es mucho más amplio que la definición de noticia internacional que se maneja tradicionalmente en los canales de televisión. Esta última incluye principalmente noticias sobre las relaciones internacionales entre países, la política interna de países extranjeros y noticias sorprendentes o entretenidas provenientes desde el exterior. En el siguiente análisis se hablará de noticias extranjeras cuando se refiera al sentido amplio y de noticias internacionales en el segundo sentido, más restringido.

El análisis de contenido cubre cuatro semanas entre enero y abril de 2008: las del 20 al 26 de enero, del 10 al 16 de febrero, y del 2 al 8 y del 23 al 29 de marzo. Los investigadores a cargo del estudio en cada país determinaron cómo dividir los noticieros en unidades individuales de acuerdo con un procedimiento convenido. Así, cada

${ }^{1}$ Los miembros del equipo de investigación son Knut De Swert (Bélgica), Paolo Mancini y Marco Mazzoni (Italia), Agnieszka Stepinska (Polonia), Thomas Hanitzsch y Angie Vu (Suiza), Joseph Chan y Baohua Zhou (China), Christine Heimprecht, Thorsten Quandt, Thilo von Pape y Jürgen Wilke (Alemania), Francis Lee (Hong Kong), Eddie Kuo y Xiaoge Xu (Singapur), Ven-hwei Lo y Tai-Li Wang (Taiwán), Jacques Alkalai Wainberg (Brasil), Constanza Mujica y William Porath (Chile), Abby Goodrum y Elizabeth Godo (Canadá), Lars Willnat y David Weaver (Estados Unidos), Akiba Cohen (Israel), Antonio Belo (Portugal) y Youichi Ito (Japón). 
noticia fue identificada a partir de criterios de contenido y de formato: las noticias se distinguen unas de otras cuando el tema o la ubicación de la historia cambia, lo que por lo general es apoyado por puntos de quiebre formales. Ejemplos típicos de noticia o ítem noticioso son informes editados consistentes en una introducción hecha por el conductor del noticiario, un reporte con voz en off del periodista y, en algunos casos, un breve comentario posterior; los ítems en un bloque de noticias -por ejemplo, un bloque internacional-, separados entre sí por una breve indicación visual (flash, fading, etc.) o un sonido específico; y entrevistas en el estudio, en vivo o grabadas, con un periodista o expertos comentando eventos de actualidad.

Todas las noticias identificadas de esta forma fueron codificadas utilizando un código extensivo de 80 variables, el que fue traducido a los idiomas de cada uno de los países participantes por los investigadores respectivos. Cada noticia se clasificó considerando los siguientes elementos:

- Tema (hasta tres temas por cada noticia)

- Duración e importancia en el noticiero (ubicación, presencia en titulares, avances o resúmenes)

- Estilo de presentación y visualización (aspectos formales como entrevista, bloque de noticias, utilización de material de agencias noticiosas y uso de elementos visuales como tablas, gráficos, etc.)

- Uso de elementos sensacionalistas (música de fondo, cámara lenta o rápida, presentación de emociones extremas o imágenes sangrientas)

- Perspectiva temporal e impacto potencial del evento

- Naturaleza de las noticias en términos de su carácter doméstico o extranjero

- Para las noticias extranjeras: países y organizaciones involucrados, uso de elementos de domesticación (referencia a ciudadanos del país de emisión del noticiero o impacto potencial del evento en dicho país)

- Conflicto (naturaleza del conflicto, partes involucradas, presencia de negociaciones, violencia y daños)

- Actores (individuos o grupos que aparecen en la noticia)

Dentro de los requisitos del proyecto Foreign TV News Around the World se acordó analizar dos canales por cada país participante: al equivalente funcional del canal (estatal) de servicio público y al canal privado comercial de mayor rating. Esta decisión se tomó bajo el supuesto de que, por su misión y financiamiento, ambos modelos ofrecen diferentes criterios para la selección y tratamiento de las noticias en general, y de las extranjeras en particular (véase, por ejemplo, HOLz-BACHA y NORRIS, 2001).

En el caso de Chile, el equivalente funcional de la estación de servicio público es Televisión Nacional de Chile (TVN), canal creado en 1969 como empresa del Estado y que, hasta 1992, dependió del gobierno. Ese año se reformó su estatuto legal convirtiéndose en un medio plural e independiente del gobierno de turno, pasando a ser una red pública del Estado, aunque financieramente autónoma (FuENZALIDA, 2000). Para efectos de este estudio se determinó comparar a TVN con MEGA (fundado en 1990 como el primer canal de TV privado del país), la estación privada y con fines abiertamente comerciales con mejores resultados de rating al momento de diseñar esta investigación. 
Para analizar las percepciones del público respecto de las noticias que provienen del extranjero, en Chile se efectuó una encuesta telefónica, probabilística, en zonas urbanas, a hombres y mujeres entre 18 y 90 años residentes en 18 ciudades de Chile (incluyendo la capital Santiago $)^{2}$. Las entrevistas se efectuaron entre el 22 de septiembre y el 9 de octubre de 2009, aplicando un cuestionario acordado por el equipo internacional del proyecto. La muestra final fue de 1.220 casos (el margen de error es entonces de +/- 2,81 puntos, al nivel de confianza de 0,95 y bajo el supuesto de varianza máxima).

Adicionalmente, se realizaron seis focus groups en octubre de 2009, segmentados en tres tramos de edad (Jóvenes, 20 - 29 años; Adultos, 30 - 59 años; y Mayores, 60 65 años) y dos niveles socioeconómicos (Medio, C2 y C3; y Bajo, D), y en cada uno de ellos participaron igual cantidad de hombres y mujeres. Posteriormente, en enero de 2010 y por instrucciones del equipo internacional que coordina este proyecto, se realizaron otros tres grupos, los que fueron constituidos de manera homogénea en cuanto al nivel socioeconómico -niveles Alto (C1), Medio (C2) y Medio Bajo (C3)-, aunque internamente fueron heterogéneos en cuanto a edad, manteniéndose sí la paridad de género. La idea era reproducir en cada grupo la discusión inter generacional que podría darse en una familia que juzga los noticiarios.

Para conocer de primera fuente el proceso de selección de noticias extranjeras de los canales se realizaron, además, un total de 16 entrevistas a periodistas y editores de noticieros de TVN y MEGA (ocho entrevistas por canal). Fueron escogidos editores con responsabilidades generales sobre todos los noticieros de cada canal, editores con responsabilidades sobre el noticiero central, editores y periodistas del área internacional y editores y periodistas de áreas que, según el análisis de contenido, elaboraban noticias extranjeras con frecuencia (economía, deportes y espectáculos). Además se entrevistó al comentarista de noticias internacionales de MEGA.

\section{Cuantificación y valoración de las noticias extranjeras en la televisión}

A partir del análisis de contenido, es posible afirmar que la televisión chilena tiende a tener un bajo nivel de noticias exclusivamente extranjeras. Sólo hay otros cuatro canales en la muestra que tienen menos noticias extranjeras que los dos canales chilenos. Esto llevaría inicialmente a clasificar la televisión chilena como parroquial o etnocéntrica (véase SchULZ, 2001). Sin embargo, al mismo tiempo se observa un nivel ligeramente más bajo que el promedio en las noticias exclusivamente domésticas de ambos canales, en comparación con el resto de la muestra (ver tabla 1).

Para analizar más en detalle esta situación, el proyecto Foreign TV News Around the World, en el cual se inserta este trabajo, clasificó la naturaleza del evento informado en cuatro categorías:

2 Todas eran ciudades de más de 95.000 habitantes y cuya población en conjunto representa cerca del $50 \%$ del total de la población del país.

3 Esta clasificación resulta entonces similar, pero en ningún caso idéntica, a una utilizada por SCHULZ (1976: 133) para medir etnocentrismo en un índice de valor noticioso (citado por SCHULZ 1996: 55) y a otra utilizada por el mismo autor en un estudio sobre noticias extranjeras en la prensa escrita (SCHULZ, 2001). 
- Doméstica: eventos que ocurren dentro del país de emisión y sin ninguna participación ni referencia a extranjeros u otros países;

- Doméstica (con participación) extranjera: eventos que ocurren dentro de las fronteras, pero con referencia a extranjeros;

- Extranjera (con participación) doméstica: eventos que ocurren en el extranjero, pero que hacen referencia a nacionales del país que emite;

- Extranjera: eventos que ocurren en el extranjero sin ninguna participación de nacionales.

Respecto de esta variable, la prueba de confiabilidad arrojó un Alpha de Krippendorff de 0,89 , considerando la variable como ordinal (calculado con el programa Kalpha 2.1, macro para SPSS, actualizado el 15 de julio de 2007, escrito por Andrew F. Hayes). Respecto de la Kappa de Cohen, su valor mínimo en las 6 comparaciones posibles $^{4}$ fue de 0,72 y el máximo de 0,82 , con un promedio de 0,78 , lo que es considerado una coincidencia sustancial (VIERA y GARRETT, 2005).

Los resultados comparados con los de todos los países analizados confirmarían la tesis del "regionalismo universal" de Schulz (1983): lo "local" siempre jugará el rol más importante en la cobertura de las noticias (citado en ROESSLER, 2003: 5).

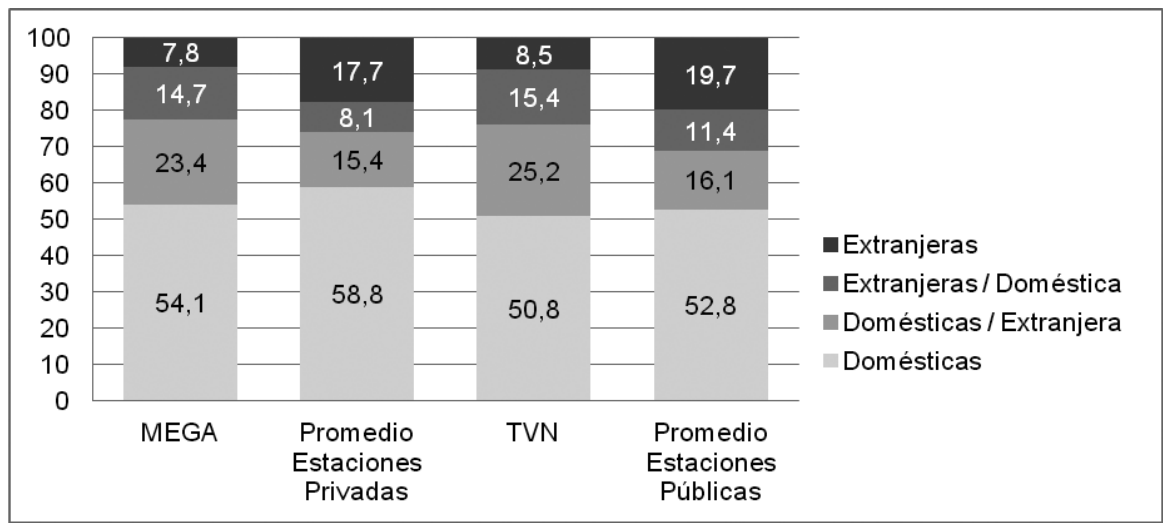

Gráfico 1. Distribución del tiempo dedicado a noticias domésticas y extranjeras ${ }^{5}$

El canal comercial de Chile registra la mitad de la dedicación en tiempo a las noticias extranjeras que el promedio de todos los canales comerciales de la muestra ( $7,8 \%$ de su tiempo de emisión, comparado con el 17,7\%). También presenta una menor dedicación a noticias exclusivamente domésticas que el promedio del grupo, porque le dedica un mayor tiempo a categorías intermedias $(38,1 \%$ frente a $23,5 \%$ del promedio de las otras estaciones privadas analizadas en el estudio). La dedicación de tiempo a estas categorías intermedias resulta un atributo particular del caso chileno,

${ }^{4}$ En el caso de Chile, se refichó una muestra de 154 noticias por los cuatro codificadores participantes en el estudio.

${ }^{5}$ Además de los dos canales chilenos, la tabla incluye datos agregados de Canadá, Estados Unidos, Brasil, Hong Kong, China, Taiwán, Singapur, Israel, Italia, Bélgica, Polonia, Alemania, Suiza y un país africano (en total son 28 canales). 
pues la alta dedicación a las categorías intermedias también se da en el canal público de Chile (40,6\% del tiempo), pero se le dedica un menor tiempo a las noticias domésticas $(50,8 \%)$ y más tiempo a las noticias extranjeras $(8,5 \%)$ que en la estación comercial. Sin embargo, esta última cifra es menos de la mitad que el promedio de todas las estaciones públicas de la muestra, que le dedican un $19,7 \%$ de su tiempo a noticias puramente extranjeras.

Para resumir el peso de la dimensión local por sobre la foránea en la construcción de la agenda noticiosa de todos los canales de la muestra -un etnocentrismo que puede expresarse no sólo en el interés por noticias domésticas, sino también en la dedicación a noticias extranjeras en las cuales el país local está envuelto, lo que Elliot y Golding llamaron "home news abroad" (1974, citado por SREBERNY-MOHAMMADI et al., 1985: 14)- se construyó un Índice de Etnocentrismo. Éste va de 1 a 4, siendo 1 puramente extranjero y 4 puramente doméstico. Los canales chilenos no están entre los más etnocéntricos -ambos canales presentaron un índice de 3,2, frente al 3,7 del canal más etnocéntrico- dada la dedicación relativamente alta a las categorías intermedias. Están, en todo caso, sobre el promedio y muy lejos de los canales con bajos niveles de etnocentrismo (Tabla 2).

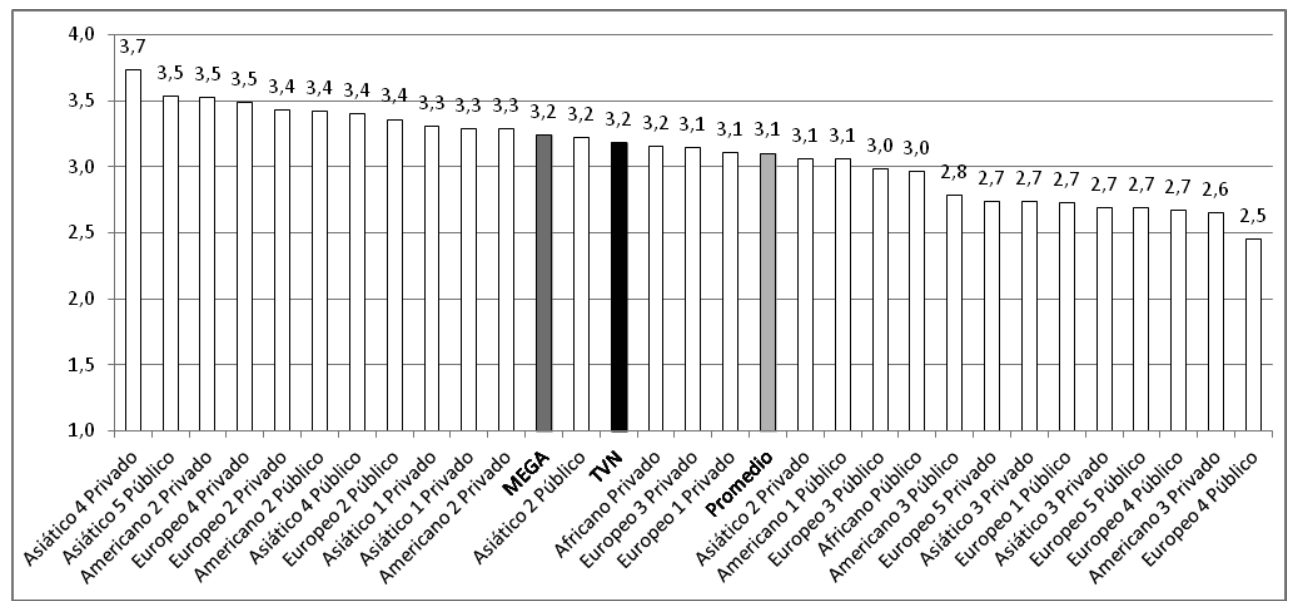

Gráfico 2. Índice de Etnocentrismo

Por su parte, editores y periodistas de los dos canales de televisión analizados en Chile reconocen que, en un contexto comercial competitivo como el del sistema televisivo chileno, el atraer audiencias masivas -medidas por medio del rating-está al centro de muchas de las decisiones periodísticas. En una percepción que coincide con lo manifestado por el público en los focus groups realizados en este proyecto, los productores de noticias atribuyen a los espectadores una falta de interés por las informaciones provenientes del extranjero. Esta percepción ha redundado en la disminución de la presencia de noticias extranjeras en la pauta a sólo una o dos diarias. Esta percepción es confirmada en el análisis de contenido que, como ya se dijo, demuestra que el tiempo dedicado a las noticias extranjeras ubica a los canales chilenos en los lugares 25 y 26 de los 30 analizados. 
En TVN no hay una proporción fija de noticias internacionales, pero sí un promedio relativamente estable de dos o tres notas por noticiario. Este número es algo mayor en los otros noticiarios del canal y en otras plataformas como Internet y el canal de noticias en el cable. Esto es visto como una oportunidad por algunos periodistas: el noticiario central les permitiría conectarse con públicos masivos y el menor espacio destinado sería un desafío positivo que los obliga a lograr esa conexión con una buena selección de temas y un desarrollo que logre captar e informar a dicha audiencia (sólo un periodista lamentó el hecho criticando una discriminación negativa hacia las noticias extranjeras en el noticiario central). Varios periodistas, en especial los del área internacional, ven esta sección como esencial dentro de la misión del canal. Por lo mismo, sugieren que ésta se puede hacer más atractiva a través del tratamiento narrativo. Si bien se estima como deseable una mayor cobertura internacional, se entiende claramente que ello no es posible, ya que estas noticias no son atractivas en términos de audiencia. Se percibe que el público suele decir que quiere más noticias internacionales, pero después no las consume.

En MEGA, a mediados de 2009 se eliminó el bloque internacional del noticiario central por falta de rating y se jibarizó el departamento internacional: hoy sólo una periodista se hace cargo de la sección y no hay un editor especializado. El bloque se sustituyó por un número variable de noticias internacionales, o incluso ninguna si es que no les parece que haya alguna que se ajuste a los parámetros definidos. Al igual que en TVN, la incorporación de más noticias internacionales se ve como un ideal improbable de realizar, porque el público no parece interesado en estos temas. Se ve la alternativa de ubicarlas con más cuidado en el noticiario, pero ello implicaría hacer una contraprogramación más cuidadosa.

Esta falta de interés por parte del público se atribuye a la falta de cercanía y de compromiso directo del público local con los eventos internacionales, y que se incrementa en Chile por un cierto insularismo de nuestra cultura. Los responsables de la producción de noticias también hablan de un creciente exitismo y narcisismo de los chilenos.

Las visiones que tienen los editores y periodistas sobre la relación del público con los eventos extranjeros tienden a coincidir con lo encontrado en esta investigación. El público, en general, valora escasamente las noticias provenientes del extranjero. En los focus groups, al momento de pedir a los participantes que ordenaran una serie de informaciones con el criterio que utilizarían si fueran editores de un noticiario de TV, ellos tendieron a jerarquizar las informaciones internacionales en el último lugar. Estas noticias se percibían como distantes, poco vinculadas con las dificultades y necesidades cotidianas del chileno. Como dijeron dos participantes: H: Sí, que hay que darle prioridad a las cosas... M: A las cosas de acá, hay que partir por casa. De hecho, en la encuesta, al pedírsele al publico que evaluara su interés por siete temas diferentes, el público siempre mostró notoriamente más interés por un tema cuando éste ocurría en Chile a que cuando ocurría en el extranjero.

En este contexto es importante destacar que el público tiene una apreciación que es correcta respecto del tiempo que los canales dedican actualmente a las noticias que provienen del extranjero en sus noticieros, según muestra nuestra encuesta: una mayoría (52\%) afirma que ellos dedican menos del $20 \%$ y un $28,9 \%$ estima que dedican 
entre $20 \%$ y $40 \%$ de su tiempo a estas noticias. De hecho nuestra medición arrojó que TVN dedica un $23,9 \%$ de su tiempo a noticias que provienen del extranjero (con o sin participación de chilenos) y MEGA el 22,5\%. La misma encuesta muestra que el público está mayoritariamente de acuerdo con esa política de los canales: el público que esperaría mayor tiempo en los noticieros para este tipo de noticias llega al 33\%, mientras $46,3 \%$ opina que el tiempo que actualmente ellos perciben se destina a estas noticias es adecuado, y un $14,4 \%$ cree que debiera disminuir.

Es decir, en términos generales, el público se muestra satisfecho con la actual posición de las noticias extranjeras en los noticiarios centrales.

Pero a pesar del menor valor atribuido a las noticias extranjeras, la mayoría del público está de acuerdo con que en definitiva estos hechos sí les afectan y que por eso deben tener un lugar en los noticieros. Esto es más notorio entre los más jóvenes, mientras que para los mayores estas noticias caben más bien dentro del concepto "cultura general". Y si bien hay satisfacción con el tiempo que actualmente los noticiarios asignan a las noticias extranjeras, en algunos casos los participantes de los focus sí demandaban mayor profundidad en su tratamiento. En ese sentido hay que señalar que la encuesta muestra que un grupo cercano al $50 \%$ reconoce su falta de dominio o capacidad para entender las noticias extranjeras.

Este interés es incluso más restringido en el caso de las noticias internacionales. En la encuesta, al considerar los temas por los que el público manifiesta menor interés cuando se trata de información proveniente del extranjero, destacan la situación de la política interna de otros países, así como las relaciones internacionales de ellos. Dado que ambos temas tienden a ser el núcleo de lo que la prensa chilena ha entendido tradicionalmente como la sección "internacional" de los noticiarios y servicios informativos, esta situación explicaría la declinación de dicha sección en los noticiarios de la TV chilena. De hecho el tema de las relaciones internacionales sólo tiene mayor importancia para el grupo que se informó por medios diferentes a la TV, y tiene levemente menos importancia que los deportes para el grupo que usa la TV combinada con otros medios para informarse.

\section{La proximidad como factor de selección y de interés por las noticias extranjeras}

En las respuestas de periodistas, editores y público se insiste en la importancia de la proximidad al momento de seleccionar noticias, particularmente las extranjeras.

Para el público lo próximo sería aquello que, pese a ocurrir en un país extranjero, afecta, de algún modo, a los chilenos. Esto, tanto desde un punto de vista muy concreto (que afecte físicamente a un chileno), como una mirada más elaborada: que revista una importancia más global para el país y los chilenos.

El análisis de contenido demuestra la alta presencia de este tipo de factores en las notas que se emitieron en el período de la muestra. En general, parece claro que el principal factor para la selección de noticias extranjeras en la televisión chilena es la participación de ciudadanos o de intereses chilenos en ellas. Cerca de dos tercios del tiempo dedicado por los noticieros chilenos a eventos que ocurren en el extranjero tienen esta característica (ver tabla 1). 
En relación con la proximidad geográfica, en la televisión chilena cerca de un cuarto del tiempo dedicado a las noticias foráneas (categorías "noticias extranjeras" y "noticias extranjeras con participación doméstica" en la variable "naturaleza del evento") corresponde a países vecinos (que comparten fronteras). Así, y congruente con la evidencia de la literatura (Wu, 2003; JONES, 2008), este hecho no parece ser el factor más importante en la selección de las noticias extranjeras en Chile. La proximidad geográfica per se no sería el factor dominante en la selección de noticias extranjeras (Roessler, 2003: 6). Esta cifra coloca a Chile cerca del promedio de la muestra (tabla 3), pero se debe destacar que ocho de los canales considerados le dedican a sus países vecinos más de un tercio del tiempo asignado a noticias que provienen del extranjero.

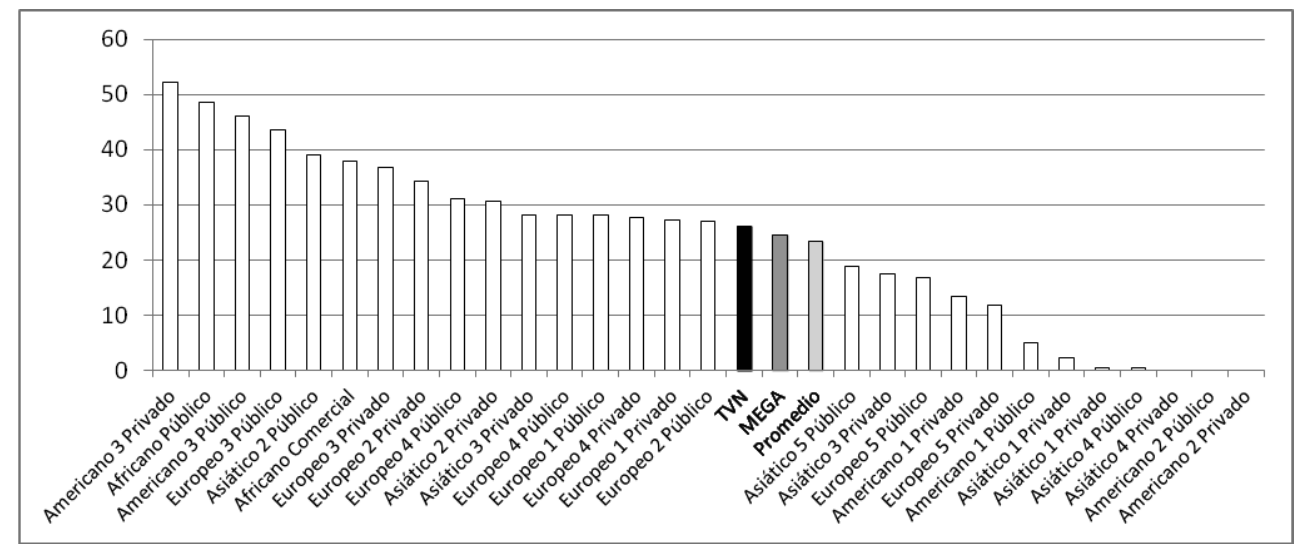

Gráfico 3. Porcentaje de noticias provenientes del extranjero en que uno o más de los países involucrados son limítrofes ( $\%$ del tiempo)

Pero el análisis de contenido muestra de manera más específica un patrón de proximidad emocional o de identificación personal, dado que la presencia de deportistas nacionales anotando en ligas de fútbol extranjeras o ganando torneos de tenis alrededor del mundo es una variable importante en la selección de noticias extranjeras en el caso chileno -en las noticias extranjeras con participación doméstica hay un claro dominio de los deportes: sobre el 50\% del tiempo es dedicado a este tema-. Este factor puede ser entendido como un elemento de proximidad emocional.

Así, la proximidad geográfica o cultural no sería el factor central en la selección de las noticias extranjeras en Chile, sino otra forma de proximidad, aquella que proviene del sentimiento de que los chilenos están "haciendo historia" más allá de sus fronteras y que sería otra expresión del llamado "Efecto Aberdeen", llamado así en referencia a un periódico de dicha ciudad escocesa, que al informar de la tragedia del Titanic tituló: "Hombre de Aberdeen perdido en el mar" (WeischenBerG, 1995: 152, citado por RoESSLER, 2003: 7).

Sin embargo, si se consideran todos los países mencionados como país de localización de un evento noticioso, sin contemplar la duración del ítem, la proximidad geográfica, en un sentido menos estricto que ser fronterizo o no, aparece sin embargo 
como relevante en Chile: países de Latinoamérica como Argentina, Brasil, Colombia, México y Venezuela son citados con frecuencia.

La proximidad cultural, medida a través de un idioma compartido (WU, 2003; WU, 2000), flujos turísticos y de inmigración (VAN BELLE, 2000), entre otros indicadores, es otro factor considerado por la literatura sobre noticias extranjeras. La relevancia de esta variable es confirmada para el caso chileno. España, la antigua autoridad colonial con la cual Chile comparte el idioma y mantiene fuertes lazos políticos y culturales, aparece como el tercer país más mencionado, apareciendo en más del 11\% de las noticias extranjeras en los dos canales analizados

En general, los datos de la encuesta confirman que el interés que el público chileno puede llegar a tener por recibir información de hechos provenientes del extranjero está mediado por estos mismos criterios de cercanía, ya sea geográfica o humana emocional. Al consultar por los países extranjeros en que el público está más interesado en informarse, los países más mencionados espontáneamente por los encuestados son los mismos que recupera el análisis de contenido (como Estados Unidos, Argentina, Perú, Bolivia, España y Brasil); entre los seis que logran el mayor interés (en cinco menciones espontáneas) se encuentran nuestros tres países limítrofes. La presencia de Estados Unidos avala la hipótesis de peso económico y militar de los países en el concierto internacional, y la hipótesis de la cercanía cultural explicaría por qué España es el primer país europeo en aparecer en la lista. Brasil representa una superposición de factores de cercanía física y poder económico dada su situación de potencia subregional.

Sin embargo, en los focus groups surgieron algunas críticas por un desequilibrio geográfico en la entrega de las informaciones internacionales, donde se privilegiaría la entrega de información de los países más poderosos, como Estados Unidos, en desmedro de la realidad del tercer mundo.

Los periodistas y editores mencionan a los mismos países al responder sobre sus patrones de cobertura de noticias extranjeras. Por sobre la relevancia del tema se valora la cercanía que el evento extranjero tenga con Chile. Esto afecta la selección de los países sobre los que se informa: primero, los fronterizos, luego el resto de América Latina, Estados Unidos y España.

La coincidencia con las prioridades informativas de los canales, ya señalada en el análisis de contenido y en las entrevistas a editores y periodistas, y confirmada en las entrevistas con sus editores y periodistas, resulta interesante también desde el punto de vista de la relación circular entre medios y receptores. Se podría decir que la televisión se adecua a las necesidades del público, pero también es fácil suponer que el público define sus prioridades y expectativas a partir de su amplia experiencia con la televisión, en un proceso que tendería a reinfluenciarse mutuamente.

\section{Impacto y sensacionalismo: atracción de audiencias masivas}

El sensacionalismo constituye un atributo particularmente relevante en el caso de la televisión y ha sido definido aquí a partir de los estudios de GraBE (GrABE, ZHOU, LANG \& Bolls, 2000; Grabe, Zhou \& BARnetT, 2001). Se entienden como sensacionalistas todos aquellos elementos formales (movimientos de cámara como el zoom 
o efectos de post-producción como la introducción de audio o de manipulaciones visuales) y de contenido (asignación de relevancia a eventos criminales, accidentes, desastres, noticias de celebridades, escándalos y sexo; que tienen el potencial de sorprender y entretener) que apelan primariamente a los sentidos del espectador antes que a su razón (GRABE et al., 2001). Para el análisis de contenido se construyó un Î́ndice de Sensacionalismo sumando variables que medían la presencia de elementos audiovisuales utilizados para promover una respuesta emocional del televidente ${ }^{6}$, ponderados según la duración del ítem noticioso. El índice va desde 0 , indicando la total ausencia de elementos sensacionalistas, a 10, cuando están presentes todos los elementos considerados. La muestra en general se caracteriza por un bajo nivel de uso de estos factores, pero en ese contexto, los canales chilenos son los que más elementos utilizan por minuto de emisión (1,3 la estación pública y 0,8 el canal comercial). Esto significa que en promedio, ambos canales tienden a usar un elemento audiovisual que favorece el sensacionalismo por minuto de emisión.

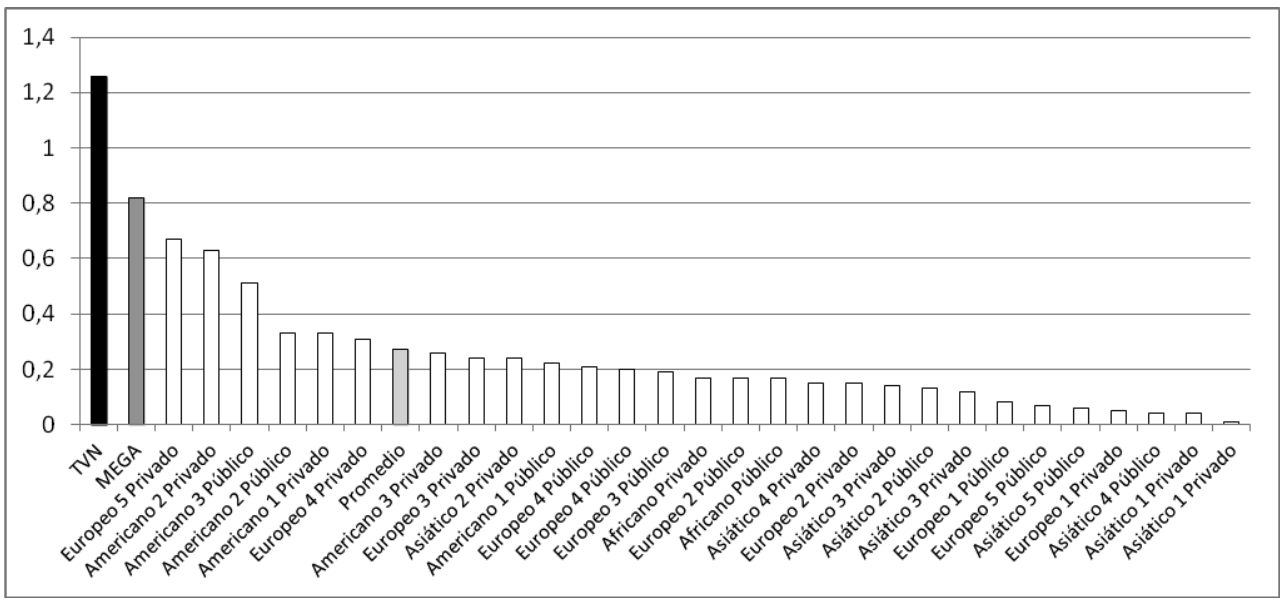

Gráfico 4. Índice de Sensacionalismo

Los editores y periodistas no hablan de sensacionalismo, pero sí de la importancia del "impacto" como factor de selección. El concepto de impacto aparece vinculado a la fuerza de las imágenes y al interés masivo de los temas reporteados. El primer elemento aparece como inseparable del carácter audiovisual del medio televisivo y a su capacidad de vincularse emocionalmente con los espectadores:

"La imagen es la que manda tu noticiario, o sea, tú entenderás que en un día de una gran tragedia, de una catástrofe, obviamente la imagen es la que manda" (editor, MEGA).

"Yo creo que tiene que haber sobre todo en la TV que es tan sensible, tan emotiva, la imagen apela tanto... no tanto a la razón sino que muchas veces a la emocionalidad del te-

${ }^{6}$ Las variables utilizadas fueron "uso de música de fondo dramática", "cámara lenta", "cámara rápida", "repetición de imágenes", "imágenes gory", "foco difuso", "cambio de color", "voz humana distorsionada", "emoción extrema" y "uso de digitalización para ocultar la identidad de una persona", todas ellas variables dicotómicas. 
lespectador [...] Mientras más factor humano tiene una noticia por supuesto que es más atractiva. [...] Mientras más rostro tiene, más atractivo es en televisión. No podemos construir algo a partir de una no cara, de hecho, hay casos en que a veces no tenemos imagen, no sabemos quién es, no hay identidad y los desechamos" (periodista, TVN).

El impacto es entendido por los profesionales también como una característica de los temas reporteados, ya sea por su potencia emocional o por su valor de entretención. En ese sentido, las noticias internacionales se ven como una mezcla de notas duras (escogidas por su trascendencia y asociadas a temas de política y economía mundial) y blandas (escogidas por su valor de entretención y que incluye notas curiosas). Los temas blandos se definen como "inter entretenido", como lo "que refresca la pauta". Junto a estas notas curiosas se añaden otras que sugieren vínculos emocionales con el público, y lo impactante. Se busca la cercanía, a través de la participación de chilenos en las noticias extranjeras o del contacto emocional, por medio de historias que evoquen emociones que trasciendan fronteras.

El público recupera esta noción de impacto. Éste es entendido al menos, en dos dimensiones principales: como un evento dramático -desastres naturales, accidentes o hechos delictivos que generan conmoción- o como el alcance, en el sentido que el hecho informado afecte a un gran número de personas. Sobre todo la primera acepción es vinculada por la audiencia con aquellas cosas que capturan la atención de la audiencia. El público reconoce el interés por este tipo de noticias, pero también se constata la importancia que tiene para los canales como una forma de captar rating que, en definitiva, sería el interés que predomina en la jerarquización de las informaciones al interior de los noticiarios.

En el caso de las noticias provenientes del extranjero, editores y periodistas vinculan las nociones de impacto y relevancia para las personas de los hechos reporteados con la teoría de los umbrales. Precisamente por la lejanía inherente a los hechos internacionales, los periodistas y editores entrevistados sostienen que los hechos extranjeros deben tener niveles más altos de relevancia e impacto que las domésticas para ser considerados en el noticiario. Sin embargo, se plantea que los umbrales pueden bajarse con el tratamiento de la información: entregando elementos de impacto, cercanía -a través de procedimientos de domesticación- y contexto.

\section{Domesticación}

Según la literatura, la domesticación es la capacidad de proveer elementos visuales, entre otros, que proveen un contexto que "hace estos eventos comprensibles, atractivos y relevantes a audiencias domésticas; y segundo, construyendo los significados de estos eventos en formas que son compatibles con la cultura y con la ideología dominante de las sociedades que sirven" (GUREVITCH et al., 1991: 206 en ClaUSEN, 2004: 28).

Entre editores y periodistas la domesticación es uno de los principales recursos para atraer al público hacia las noticias extranjeras y para hacerlas más comprensibles. Esta percepción se ve fundamentada cuando se analizan los resultados de la encuesta. Cuando se pregunta por el interés en general por noticias acerca de otros países, sólo un 33\% de los entrevistados se declara muy o bastante interesado, fracción que salta a 53,5\% cuando se repite la pregunta pero precisando "si en ellas participan chile- 
nos". La presencia de connacionales en eventos que ocurren en el extranjero es, en todo el mundo, una forma de obtener una proximidad emocional con un hecho que ocurre distante físicamente (es un factor de domesticación).

A través de la domesticación sería posible rebajar los umbrales más altos de conflicto, relevancia, impacto o factor humano que se les exige a la noticias internacionales, e incluir en la pauta noticias que a priori podrían tener niveles insuficientes como para entrar en la agenda informativa. Sin embargo, entre los profesionales la domesticación no es vista como un valor en sí misma. Se percibe que la domesticación muy evidente a través de eventos que no tienen vinculación directa con Chile puede ser de mal gusto. En esos casos, se prefiere un acercamiento emocional a través de la fuerza de las imágenes o de la relevancia del hecho en sí.

\section{Contexto}

En el análisis de contenido, para analizar la capacidad de cada canal para contextualizar su información entregando referencias a antecedentes y a consecuencias esperadas se construyeron dos índices. Las referencias al tiempo fueron codificadas de $1 \mathrm{a}$ 6 , desde la ausencia de referencias al tiempo hasta referencias de más de un año hacia el pasado o el futuro, según la variable. El índice representa el promedio de la variable, ponderado según la duración del ítem.

La tendencia general en los países analizados es a tener más referencias al pasado que al futuro, con algunas excepciones. En este contexto, los dos canales chilenos se ubican en una posición intermedia en ambos índices. En términos de las referencias al pasado, el canal público tiene un índice de 3,7, que indica que su promedio está cerca de la entrega de antecedentes del mes anterior al del evento noticioso. El canal comercial tiene un lapso de referencia algo más corto: 3,2 , que lo deja más cerca de las referencias a la semana anterior. En términos de las alusiones al futuro son similares (2,7 la estación pública y 2,64 el canal comercial), haciendo referencia a la semana siguiente al evento noticioso.

Paradójicamente, considerando que a raíz de su falta de proximidad podrían requerir mayores explicaciones, a las noticias extranjeras se les da la menor cantidad de contexto. Sin embargo, este resultado es coherente con el bajo nivel de importancia que se les da en Chile a las noticias puramente extranjeras, medido, por ejemplo, por la cantidad de tiempo dedicada a ellas, especialmente cuando se le compara con la alta proporción de tiempo dedicada a las categorías intermedias. La TV chilena en general, y la estación pública en particular, también le pueden estar dando mayor importancia a las dos categorías intermedias al contextualizarlas, y/o al escoger aquellas que tienen más proyecciones hacia el pasado y el futuro que las noticias exclusivamente extranjeras.

La posición intermedia de los canales en cuanto a contextualización, en la comparación internacional, va en la línea de una de las principales críticas del público hacia las noticias manifestadas en los focus groups, la que tiene que ver con una eventual superficialidad con que se tratan las informaciones, la cual es atribuida a una falta de tiempo. A la falta de contexto que permita integrar y comprender mejor la información, se agregan críticas a la falta de seguimiento de las noticias y la falta de puntos de vista 
diferentes que permitan tener una visión más completa de los hechos. Sobre las noticias extranjeras, la encuesta muestra que el público está dividido respecto de su capacidad para entender este tipo de informaciones: el $45,4 \%$ está muy o algo de acuerdo con que no tiene suficientes antecedentes para ello, pero el 43,6\% rechaza dicha afirmación (muy o algo en desacuerdo).

Periodistas y editores atribuyen la falta de contexto a las características propias del medio, que entrega poco tiempo para las noticias extranjeras, y del lenguaje audiovisual, que potencia el valor emocional de las imágenes por sobre los argumentos racionales -a diferencia de los diarios, dicen-.

Las soluciones ofrecidas por cada canal a la necesidad de mayor contexto son diferentes. MEGA ha mantenido la figura del comentarista de noticias internacionales, que analiza la contingencia todos los días en la edición matinal del noticiario y los sábados en el noticiario central. Además se ve en el envío de corresponsales, infrecuente debido a los altos costos y las dificultades logísticas de hacerlo, una alternativa para entregar contexto.

En TVN el envío de corresponsales es igualmente eventual y se confía que la emisión frecuente de ciertos temas haga menos necesario el contexto para la comprensión de los hechos reportados. Además se menciona insistentemente la importancia de las imágenes, que permiten un vínculo emocional que haría innecesario el contexto. Por ejemplo, se explica que la imagen de un niño abandonado en medio de una inundación implica un vínculo tan potente con el espectador que hace menos relevante la información sobre la localización o las causas de la catástrofe.

\section{Conclusiones generales}

La revisión de los resultados de todas las etapas de este proyecto -considerando lo sostenido por los responsables de la difusión de noticias, lo que efectivamente se emite y las percepciones y valoraciones del público- muestra importantes coincidencias. Éstas van en la línea de confirmar para Chile la hipótesis de la primacía de lo local en la pauta informativa. La relativamente baja -en términos comparativos con el resto de los países participantes en el estudio- presencia de las noticias extranjeras del tipo que tradicionalmente se llama "política internacional", detectada en el contenido de los noticiarios chilenos, es congruente con el bajo interés que el público muestra por este tipo de informaciones. Este factor es reconocido por editores y periodistas, y ha redundado en el empequeñecimiento de las secciones y bloques internacionales que presentan los noticiarios.

En las distintas etapas del estudio también hubo coincidencia acerca de los factores que inciden en la selección de las noticias extranjeras, y en los temas que deben tratarse con mayor prioridad. En un contexto en que lo local prima sobre lo extranjero, público y emisores (periodista y editores) concuerdan en que el "impacto" es un primer factor en la construcción de la pauta, entendido en primer lugar como lo dramático y en segundo lugar como el alcance o relevancia para grandes grupos de ciudadanos (como salud y educación). Se confirmó, así, la relevancia de los procedimientos de proximidad geográfica y emocional en la selección de las noticias extranjeras. El público insistió en que la cercanía es el principal factor en su valoración de 
las noticias, mismo elemento mencionado por editores y periodistas y que, en el análisis de contenido, fue reconocido con frecuencia en el material que efectivamente salió al aire (por ejemplo, en la importancia comparativa que tienen las noticias extranjeras con participación de nacionales en nuestros noticiarios).

Específicamente en relación con las noticias provenientes del extranjero, el estudio confirma que tanto para emisores y público, la hipótesis de los umbrales más altos es la norma: estas noticias deben tener más impacto dramático o mucho más alcance para posicionarse en los noticiarios. Pero por sobre esos criterios se impone claramente el de la cercanía emocional o afectiva, dada en definitiva por la participación o involucramiento de chilenos en dichos eventos, lo que tiende a asegurarles un espacio en los contenidos de los noticiarios, siendo éste un aspecto distintivo de la televisión chilena (en cuanto a contenido) si se le compara con el resto de los países participantes del estudio.

Tanto el público como los periodistas reconocen la selección de noticias impactantes (dramáticas) como un modo de atraer la atención del público -vinculada a la masividad y a altos índices de audiencia- hacia eventos distantes geográficamente. Esto parece congruente con los niveles levemente más altos de sensacionalismo de los noticiarios chilenos en comparación con los de los demás países analizados. Sin embargo, específicamente las noticias extranjeras no tienen niveles más altos de sensacionalismo que el resto de las informaciones emitidas por los noticiarios chilenos. De todos modos, la encuesta mostró que el público percibe las noticias extranjeras como excesivamente negativas.

La domesticación de las noticias extranjeras a través de la mención de chilenos participantes y de consecuencias para el país es uno de los procedimientos más comunes en los noticiarios chilenos. El público reconoce, tanto en la encuesta como en los focus groups, que la participación de connacionales es un factor de mayor interés y valoración de este tipo de noticias. Los periodistas y editores reconocen el procedimiento, pero insisten en que intentan evitarlo, porque el exceso de su uso aparece como un recurso "barato".

El análisis de contenido detectó, también, una menor entrega de contexto en las noticias extranjeras. Este resultado es congruente con las críticas del público hacia la superficialidad de las noticias y las dificultades para comprender las informaciones extranjeras. Los periodistas atribuyen esta falta a la falta de tiempo para este tipo de noticias y a las características propias del lenguaje televisivo.

\section{Referencias bibliográficas}

BRAMAN, Sandra y COHEN, Akiba (1990): "Research from start to finish", en ANDERSON, James A.: Communication Yearbook, 13, Newbury Park, CA, Sage, pp. 511-518.

CLAUSEN, Lisbeth (2004): "Localizing the global: 'Domestication' processes in international news production". Media, Culture and Society, 26 (1), 25-44.

CONSEJO NACIONAL DE TELEVISIÓN (2005): Encuesta Nacional de Televisión. Principales resultados. 
FUENZALIDA, Valerio (2000): La televisión pública en América Latina. Reforma o privatización. Santiago de Chile, FCE.

GOLAN, Guy (2006): "Inter-media agenda setting and global news coverage: Assessing the influence of the New York Times on three network television evening news programs". Journalism Studies, 7 (2), pp. 323-334.

GRABE, Maria Elizabeth, ZHOE, Shuhua, LANG, Annie y BOLLS, Paul David (2000): "Packaging television news: The effects of tabloid on information processing and evaluative responses." Journal of Broadcasting \& Electronic Media, 44 (4), pp. 581-598.

GRABE, Maria Elizabeth, ZHOE Shuhua y BARNETT, Brooke (2001): "Explicating sensationalism in television news: Content and the bells and whistles of form." Journal of Broadcasting \& Electronic Media, 45 (4), pp. 635-655.

GUREVITCH, Michael, LEVY, Mark y ROEH, Itzhak (1991): "The global newsroom: convergences and diversities". En DAHLGREN, Peter y SPARKS, Colin (Eds.): Communication and citizenship: Journalism and the public sphere. London, Routledge.

HOLTZ-BACHA, Christina y NORRIS, Pippa (2001): “To Entertain, Inform and Educate: Still the Role of Public Television". Political Communication, 18 (2), pp. 123-140.

JONES, Steve (2008): “Television News: Geographic and source biases". International Journal of Communication, 2, pp. 223-252.

MARÍN, Cristóbal, “Televisión y espacio público”. Informe $N^{\circ} 2$ PNUD, 2001.

RIFFE, Daniel y BUDIANTO, Arianne (2001): "The Shrinking World of Network News". International Communication Bulletin, 36 (spring), pp. 12-35.

ROESSLER, Patrick (2003): "Pictures of our world. An international comparison of television news". Paper presented at the annual meeting of the International Communication Association, Marriott Hotel, San Diego, CA.

SCHULZ, Winfried (1996): “Inhaltsanalyse". En NOELLE-NEUMANN, Elisabeth, SCHULZ, Winfried y WILKE, Jürgen: Publizistik. Massenkommunikation, Frankfurt am Main, Fischer Taschenbuch.

SCHULZ, Winfried (2001): "Foreign news in leading newspapers of western and postcommunist countries". Paper presented at the $51^{\text {st }}$ Annual Conference of the International Communication Association, Washington D.C.

SCHULZ, Winfried (1983): "Nachrichtengeographie. Untersuchungen über die Striktur der Internationalen Berichterstattung." En RÜHL, Manfred y STUIBER, Heinz Werner (Eds.): Kommunikationspolitik in Forschung und Anwendung. Festschrift für Franz Ronneberger, Düsseldorf, Droste, pp. 281-291.

SCHULZ, Winfried (1976): Die Konstruktion von Realität in den Nachrichtenmedien. Analyse der aktuellen Berichterstattung. Freiburg, Alber. 
SREBERNY-MOHAMMADI, Annabelle y otros (Eds., 1985): Foreign News in the Media: International Reporting in 29 Countries. Paris, UNESCO.

STEVENSON, Robert L.; COLE, Richard (1984a): "Patterns of foreign news". En STEVENSON, Robert; SHAW, Donald (Eds.): Foreign news and the new world information order. Ames, Iowa: Iowa State University Press, pp. 37-62.

THOMPSON, John (1995): The media and modernity: A social theory of the media. Stanford, Stanford University Press.

VAN BELLE, Douglas (2000): "New York Times and Network TV news coverage of foreign disasters: The significance of the insignificant variables". Journalism and Mass Communication Quarterly, 77 (spring), 50-70.

VIERA, Anthony, GARRETT, Joanne (2005): "Understanding Interobserver Agreement: The Kappa Statistic". Family Medicine, 37 (5), pp. 360-363.

WEISCHENBERG, Siegfried (1995): Journalistik, Theorie und Praxis aktueller Medienkommunikation, Band 2. Opladen, Westdeutscher Verlag.

WHITNEY, Charles, FRITZIER, Marilyn, JONES, Steve, MAZZARELLA, Sharon y RAKOW, Lana (1989): "Geographic and Source Biases in Network Television News, 1982-1984." Journal of Broadcasting \& Electronic Media, 33 (spring), pp. 159-174.

WU, H. Denis (2000): "Systemic determinants of international news coverage: A comparison of 38 countries". Journal of Communication, 50 (2), pp. 110-130.

WU, H. Denis (2003): "Homogeneity around the world? Comparing the systemic determinants of international news flow between developed and developing countries". Gazette, 65 (1), pp. 9-24. 